\title{
Clinical associations of prenatal ischaemic white matter injury
}

\author{
Geraldine Gaffney, Marian V Squier, Ann Johnson, Valerie Flavell, Susan Sellers
}

\begin{abstract}
Neuropathological examinations were carried out at necropsy on 274 cases of intrauterine death or neonatal death at or before three days after birth. Fifty six $(20 \cdot 4 \%)$ subjects had evidence of prenatal ischaemic brain damage. On review of the maternal case notes to ascertain antenatal clinical associations there was an increased incidence of intrauterine growth retardation, either based on birth weight for gestational age (odds ratio (OR) 2.0; 95\% confidence interval (CI) $1 \cdot 1$ to $3 \cdot 7$ ) or diagnosed antenatally (OR $2 \cdot 7$; $95 \%$ CI $1 \cdot 3$ to $5 \cdot 6)$. Oligohydramnios was also more common (OR 2.9; 95\% CI 1.2 to $7 \cdot 0$ ). The association of intrauterine growth retardation and white matter damage remained after excluding fetuses with a major congenital anomaly (OR 2.4; $95 \%$ CI $1 \cdot 1$ to $5 \cdot 1)$. The findings suggest that chronic intrauterine hypoxia may be associated with damage to cerebral white matter among fetuses and infants who die. The relation between ischaemic white matter damage and cerebral palsy among survivors remains speculative.

(Arch Dis Child 1994; 70: F101-F106)
\end{abstract}

It is well known that ischaemic lesions of the cerebral white matter may develop during the prenatal period ${ }^{1}$ and it has been suggested that such lesions may be associated with later neurological impairment, particularly cerebral palsy. ${ }^{2-6}$ Adverse events occurring at any time throughout the prenatal period and during or after birth may interfere with the development of the brain, and the distribution and extent of cerebral injury may vary considerably with the timing of these events. Traditionally, events during the intrapartum period were thought to be responsible for the development of cerebral palsy in many children, but it is now appreciated that only about $13 \%$ of cases of cerebral palsy can be attributed to intrapartum injury. ${ }^{78}$ Although other aetiological subgroups of cerebral palsy can be identified, such as congenital malformation of the brain, postnatal infection and genetic factors, at present 'we probably do not know what causes the majority of cerebral palsy'. ${ }^{9}$

There is some evidence to support the idea that a proportion of cases of cerebral palsy may be determined antenatally. ${ }^{10-15}$ For example, it has been shown that the mothers of children who develop cerebral palsy have an increased frequency of adverse antenatal events. ${ }^{11-13}$ The association of cerebral palsy and intrauterine growth retardation (IUGR) suggests that long term intrauterine placental insufficiency may have a role in the origin of cerebral palsy in some children, ${ }^{14} 15$ whereas intrauterine vascular accidents leading to focal intracerebral damage may account for some spastic hemiplegia. ${ }^{10}$

Hypoxic or ischaemic white matter damage may occur in several forms. These range from diffuse white matter damage, either gliosis to more severe damage characterised by reactive astrocytosis, endothelial proliferation, nuclear karyorrhexis, and macrophage infiltration, probably representing early infarction, to the more widely recognised periventricular leukomalacia where there are small foci of cystic infarction in the deep white matter, usually associated with some degree of diffuse change. The term periventricular telencephalic leukoencephalopathy has been coined to describe diffuse white matter damage which may precede or coexist with periventricular leukomalacia. ${ }^{1}$ Widespread cystic degeneration of the white matter, cystic leukoencephalopathy, represents the most severe form of white matter damage. 1617

The clinical correlation between cystic periventricular leukomalacia detected by neuroimaging and later cerebral palsy is high, with $60-100 \%$ of survivors having a motor impairment. ${ }^{18-22}$ The relation between less extreme forms of white matter damage and later cerebral palsy is not so clear. The observation that only $28 \%$ of non-haemorrhagic hypoxic and ischaemic lesions detected at necropsy have been identified by ultrasound during life suggests that neuroimaging may not be sufficiently sensitive to detect minor lesions. ${ }^{23}$ This means that it is not yet possible to study the association of minor forms of ischaemic white matter damage and later cerebral palsy using clinical imaging techniques.

An alternative approach to studying the possible clinical significance of prenatal ischaemic white matter damage is to identify the antenatal, intrapartum, and neonatal clinical factors found more often among fetuses with such lesions than those without. If these factors were the same as those known to be associated with the prenatal and perinatal periods of children with cerebral palsy this would support the hypothesis that prenatal ischaemic brain lesions have a role in the origin of cerebral palsy. Furthermore, the identification of factors associated with prenatal brain damage may allow the development of preventive measures.

Since 1984 a large series of fetal and neonatal brains has been examined systematically 
at necropsy and about a fifth were found to have white matter ischaemic lesions. An earlier report described the neuropathological findings in detail. ${ }^{24}$ In this study, using a larger series of brains, we have attempted to identify the antenatal and perinatal factors which occur more often among those who are found to have ischaemic white matter damage at necropsy than among those who do not.

\section{Subjects and methods}

Two hundred and seventy four fetuses and infants who had a neuropathological examination at necropsy in Oxford between 1984 and 1991 were included in the study. The mothers of $164(60 \%)$ of the fetuses were residents of one health district; the remainder were referred from perinatal pathologists from other health districts. It was therefore a highly selected series. The cases included those who had either died in utero (139 fetuses) or in the first three days after birth (135 infants). Infants surviving longer than three days were not included as the evolution of pathological reactions in the brain would not allow clear identification of prenatal damage after this time. Terminations of pregnancy and cases where the pathology of coexisting disorders, such as cytomegalovirus infection or arteriovenous malformation, could be confused with a prenatal ischaemic lesion were excluded.

Neuropathological examination was performed by a single observer (MVS). The diagnosis of intracerebral ischaemic damage was based on finding evidence of cerebral infarction; in the more severe and longstanding cases this was readily recognised as the changes of periventricular leukomalacia. Four criteria were used to establish a diagnosis of diffuse mild or early ischaemic white matter damage. ${ }^{24}$ These criteria were reactive astrocytosis, macrophage infiltration, karyorrhexis, and endothelial swelling or reduplication. The grey matter was rarely affected in the subjects with mild ischaemic damage.

Variables such as socioeconomic group, ethnic group, maternal smoking habits, maternal age, and past obstetric history were recorded for all 274 subjects. A poor obstetric history was defined as previous intrauterine or neonatal death, previous delivery of a child with motor impairment, or late or recurrent miscarriage. Information on intrapartum events such as the findings on fetal monitoring in labour and mode of delivery was recorded for only those cases where the fetus was still alive at the

Table 1 Comparison of demographic factors and maternal history in subjects with and without ischaemic white matter damage; values are number (\%)

\begin{tabular}{|c|c|c|c|}
\hline Variables & $\begin{array}{l}\text { Lesions } \\
(n=56)\end{array}$ & $\begin{array}{l}\text { No lesion } \\
(n=218)\end{array}$ & OR $(95 \% C I)$ \\
\hline Father non-white & $7(13)$ & $22(10)$ & $1.3(0.5$ to 3.2$)$ \\
\hline Mother non-white & $8(14)$ & $17(8)$ & $2.0(0.8$ to 5.0$)$ \\
\hline Socioeconomic group $\geqslant 5$ & $11(20)$ & $33(15)$ & $1.4(0.6$ to 3.0$)$ \\
\hline Unmarried mother & $18(32)$ & $34(16)$ & $2 \cdot 5(1.3$ to $5 \cdot 0)$ \\
\hline Primigravid & $19(34)$ & $77(35)$ & $0.9(0.5$ to 1.8$)$ \\
\hline Maternal illness & $3(5)$ & 29 (13) & $0.4(0.1$ to $1 \cdot 3)$ \\
\hline History of infertility & $6(11)$ & $15(7)$ & $1.7(0.6$ to 4.5$)$ \\
\hline Poor obstetric history & $2(4)$ & $18(8)$ & $0.4(0.1$ to 1.8$)$ \\
\hline Smoking during pregnancy & $13(23)$ & $36(17)$ & $1.5(0.7$ to 3.0$)$ \\
\hline
\end{tabular}

onset of labour; neonatal information was recorded only for those alive at delivery.

Gestational age was estimated using a combination of accurate menstrual data or an ultrasound scan performed before 20 weeks' gestation. Where there was a discrepancy of more than 14 days between the menstrual data and the ultrasound estimate of gestation, the ultrasound estimate was used. The presence of intrauterine growth retardation based on an antenatal ultrasound diagnosis was recorded as 'antenatal diagnosis of IUGR'. Birth weight at delivery was recorded for all subjects based on standard centiles for gestational age for the Oxford region ${ }^{25}$; those with a birth weight at or below the 10 th centile were identified. In $75 \%$ of those with a birth weight of less than the 10th centile for gestational age there had been an antenatal diagnosis of IUGR.

Cardiotocographic data was classified using the criteria of the Dublin trial of intrapartum monitoring. ${ }^{26}$ These data were used only if monitoring had been performed continuously throughout labour and the original recording was available to the researcher.

The maternal antenatal and neonatal case notes were reviewed by a single observer (GG) blind to the presence or absence of lesions. In the first analysis the frequency of all demographic, antenatal, intrapartum, and neonatal factors were compared between the two groups (those with and those without lesions). The results of all comparisons are given as odds ratios (ORs) and 95\% confidence intervals (CIs). Continuous data were analysed using the Mann-Whitney $U$ test. A p value of less than 0.05 was taken as statistically significant.

A third of the case series had a major congenital anomaly either of the brain or elsewhere. As some of the antenatal factors being considered, such as IUGR, are known to be associated with congenital anomaly and as it is plausible that some congenital anomalies, such as congenital heart disease, might predispose to cerebral ischaemia, the presence of a congenital anomaly is a potential confounding factor. Further analysis was therefore performed to study the clinical associations of white matter lesions in those with a congenital anomaly and in those without.

\section{Results}

The case series consisted of 139 cases of intrauterine death, which included 11 cases of intrapartum intrauterine death, and 135 neonatal deaths. There were 56 cases of prenatal intracerebral ischaemic damage $(20 \%) ; 34$ $(24 \%)$ of the 139 intrauterine deaths and 22 $(16 \%)$ of the 135 neonatal deaths had lesions. Among those with lesions, only six $(11 \%)$ had cystic lesions of $1 \mathrm{~cm}$ or greater in diameter. There was no difference at the 5\% level between those with and without intracerebral lesions in maternal age or in the frequency of most demographic factors and characteristics related to maternal health and previous obstetric history (table 1 ). When single mothers were compared with married mothers there was a greater chance that the infants of the single 
Table 2 Comparison of frequency of antenatal factors in subjects with and without ischaemic white matter damage; values are number (\%)

\begin{tabular}{|c|c|c|c|}
\hline Variables & $\begin{array}{l}\text { Lesions } \\
(n=56)\end{array}$ & $\begin{array}{l}\text { No lesion } \\
(n=218)\end{array}$ & OR $(95 \% C I)$ \\
\hline $\begin{array}{l}\text { Induced conception } \\
\text { Increased maternal serum } \alpha \text { fetoprotein } \\
\text { Pre-eclampsia }\end{array}$ & $\begin{array}{l}3(5) \\
4 / 42(10)\end{array}$ & $\begin{array}{l}12(6) \\
4 / 125(3)\end{array}$ & $\begin{array}{l}0.9(0.3 \text { to } 3.6) \\
3.2(0.8 \text { to } 13.4)\end{array}$ \\
\hline All & $6(11)$ & $33(15)$ & $0.7(0.3$ to 1.7$)$ \\
\hline Severe & $2(4)$ & $13(6)$ & $0.6(0.1$ to 2.7$)$ \\
\hline Antepartum haemorrhage & $10(18)$ & $27(12)$ & $1.5(0.7$ to 3.4$)$ \\
\hline Intrauterine growth retardation & $15(27)$ & $26(12)$ & $2.7(1.3$ to $5 \cdot 6)$ \\
\hline Oligohydramnios & $10(18)$ & $15(7)$ & $2.9(1.2$ to 7.0$)$ \\
\hline Polyhydramnios & 7 (13) & 29 (13) & $0.9(0.4$ to 2.3$)$ \\
\hline Chorioamnionitis & $2(4)$ & $8(4)$ & $0.9(0.2$ to 4.7$)$ \\
\hline Premature rupture of membranes & $7(13)$ & $25(11)$ & $1.1(0.5$ to 2.7$)$ \\
\hline Prolonged rupture of membranes & $3(5)$ & $18(8)$ & $0.6(0.2$ to 2.6$)$ \\
\hline Maternal infection during pregnancy & $8(14)$ & $25(11)$ & $1.3(0.6$ to 3.0$)$ \\
\hline
\end{tabular}

Table 3 Comparison of frequency of intrapartum factors in subjects with and without ischaemic white matter damage. Based on 135 neonatal deaths and 11 intrapartum intrauterine deaths; values are number (\%)

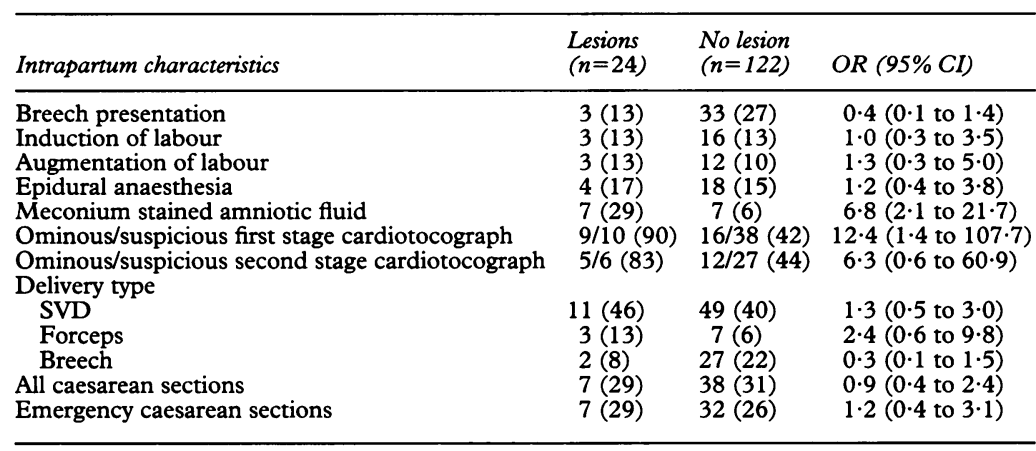

$\mathrm{SVD}=$ spontaneous vaginal delivery

mothers would have lesions (OR $2.5 ; 95 \%$ CI 1.3 to 5.0 ). The non-white mothers were twice as likely to have infants with lesions than white mothers (OR $2.0 ; 95 \%$ CI 0.8 to 5.0 ), though this was not significant at the $5 \%$ level.

\section{ANTENATAL FACTORS}

Antenatal diagnosis of IUGR (OR $2 \cdot 7 ; 95 \%$ CI 1.3 to 5.6 ) and the presence of oligohydramnios (OR $2.9 ; 95 \%$ CI $1 \cdot 2$ to $7 \cdot 0$ ) were more common in the group with lesions. Although an increased maternal serum $\alpha$ fetoprotein was uncommon, it did occur more often among mothers of infants with lesions, but was not significant at the $5 \%$ level (OR 3.2; $95 \%$ CI 0.8 to 13.4 ). The frequency of the other antenatal factors examined did not differ between the two groups (table 2 ).

\section{INTRAPARTUM FACTORS}

Analysis of intrapartum factors was performed only on those 146 cases who were alive before delivery. Meconium stained liquor was found more often among the group with lesions (OR
$6 \cdot 8 ; 95 \%$ CI $2 \cdot 1$ to $21 \cdot 7)$. Continuous intrapartum fetal monitoring was performed in the first stage of labour on $13(54 \%)$ of those with lesions and $51(42 \%)$ of those without and in the second stage in nine $(38 \%)$ of those with lesions and in $38(31 \%)$ of those without. Further analysis was confined to those in whom the complete cardiotocograph was available to the authors. An ominous or suspicious first stage cardiotocograph as defined by the criteria used in the Dublin trial, ${ }^{26}$ occurred more often among those with lesions (OR $12 \cdot 4 ; 95 \%$ CI 1.4 to $107 \cdot 7$ ) (table 3 ). Ominous or suspicious second stage cardiotocography also occurred more often among those with lesions (OR 6.3; 95\% CI 0.6 to 60.9 ), but the numbers were small and the difference is not significant at the $5 \%$ level. The mode of delivery, rates of induction of labour or augmentation, and the rate of monitoring did not differ between the two groups.

\section{NEONATAL DATA}

Mean and median birth weight and gestational age at delivery did not differ between the two groups (table 4). Analysis of the birth weight for gestational age showed that a birth weight at or less than the 10th centile was twice as frequent among those with lesions (OR $2 \cdot 0$; $95 \%$ CI $1 \cdot 1$ to $3 \cdot 7$ ) (Table 4 ). There was no difference between the frequency of major congenital anomaly between the two groups (OR $1.5 ; 95 \%$ CI 0.8 to $2 \cdot 7$ ).

One hundred and thirty five infants were alive at delivery (table 4). A five minute Apgar score of 2 or less was recorded with increased frequency among infants with lesions (OR 3.2; $95 \%$ CI $1 \cdot 2$ to $8 \cdot 5)$. Six infants with lesions $(27 \%)$ had their cord blood $\mathrm{pH}$ measured at delivery as did $35(31 \%)$ of those without lesions. There was an increased likelihood of an umbilical cord $\mathrm{pH}$ value of 7.20 or less among those with lesions, but the numbers were small and this is not significant at the 5\% level (OR $4 \cdot 2 ; 95 \%$ CI 0.7 to $25 \cdot 1$ ).

\section{PLACENTAL HISTOLOGY}

Placental histology was performed in $49(88 \%)$ of those with lesions and $171(78 \%)$ of those without. The median placental weight was $394 \mathrm{~g}$ for those with lesions and $400 \mathrm{~g}$ for those without. There was no difference at the $5 \%$ level in the frequency of acute infarction, chronic infarction, the presence of a retroplacental clot, chorioamnionitis, funisitis, and vascular anastomoses between infants with and without lesions.

Table 4 Comparison of frequency of characteristics in subjects with and without ischaemic white matter damage

\begin{tabular}{lccc}
\hline Characteristics & Lesions & No lesion & OR (95\% CI) \\
\hline All subjects & $34(23-41)^{\star}$ & $34(17-42) \dagger$ & $-\ddagger$ \\
Median (range) gestation (weeks) & $1934(572-4139)^{\star}$ & $1840(106-4390) \dagger$ & -5 \\
Median (range) weight (g) & $22(39 \cdot 2)^{\star}$ & $67(31) \dagger$ & $1 \cdot 5(0 \cdot 8$ to $2 \cdot 7)$ \\
No (\%) with congenital abnormality & $24(43)^{\star}$ & $59(27) \dagger$ & $2 \cdot 0(1 \cdot 1$ to $3 \cdot 7)$ \\
Birth weight $\leqslant 10$ th centile & $12 / 22(55)$ & $35 / 113(31)$ & $3 \cdot 2(1 \cdot 2$ to $8 \cdot 5)$ \\
Characteristic (alive at delivery only) & $5 / 6(83)$ & $13 / 35(37)$ & $4 \cdot 2(0 \cdot 7$ to $25 \cdot 1)$ \\
No $\%$ with Apgar score $\leqslant 2$ at 5 min & & & \\
No $(\%)$ with cord pH value $\leqslant 7 \cdot 20$ & & &
\end{tabular}

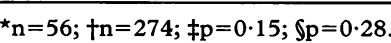


Table 5 Association of perinatal characteristics with prenatal white matter lesions among those with and withult congenital anomaly; values are number (\%)

\begin{tabular}{|c|c|c|c|c|c|c|}
\hline \multirow[b]{2}{*}{ Perinatal characteristic } & \multicolumn{2}{|c|}{ Congenital anomaly absent } & \multirow[b]{2}{*}{ OR $(95 \% C I)$} & \multicolumn{2}{|c|}{ Congenital anomaly present } & \multirow[b]{2}{*}{ OR $(95 \% C I)$} \\
\hline & $\begin{array}{l}\text { Lesions } \\
(n=34)\end{array}$ & $\begin{array}{l}\text { No lesions } \\
(n=151)\end{array}$ & & $\begin{array}{l}\text { Lesions } \\
(n=22)\end{array}$ & $\begin{array}{l}\text { No lesions } \\
(n=67)\end{array}$ & \\
\hline $\begin{array}{l}\text { Unmarried } \\
\text { Mother non-white }\end{array}$ & $\begin{array}{l}8(24) \\
6(18)\end{array}$ & $\begin{array}{l}29(19) \\
10(7)\end{array}$ & $\begin{array}{l}1.3(0.5 \text { to } 3 \cdot 1) \\
3 \cdot 1(1.0 \text { to } 9 \cdot 3)\end{array}$ & $\begin{array}{c}10(45) \\
2(9)\end{array}$ & $\begin{array}{l}5(7) \\
7(10)\end{array}$ & $\begin{array}{r}10.3(3.0 \text { to } 35.7) \\
0.9(0.2 \text { to } 4.6)\end{array}$ \\
\hline Raised maternal serum $\alpha$ & & & & & & \\
\hline fetoprotein & $3 / 26(12)$ & $2 / 89(2)$ & $5.7(0.9$ to 36.0$)$ & $1 / 16(6)$ & $2 / 36(6)$ & $1 \cdot 1(0.1$ to $13 \cdot 5)$ \\
\hline Intrauterine growth retardation & $9(26)$ & $16(11)$ & $3.0(1.2$ to $7 \cdot 6)$ & $6(27)$ & $10(15)$ & $2 \cdot 1(0.7$ to $6 \cdot 8)$ \\
\hline Oligohydramnios & $6(18)$ & $10(7)$ & $3.0(1.0$ to 9.0$)$ & $4(18)$ & $5(7)$ & $2.8(0.7$ to 11.4$)$ \\
\hline $\begin{array}{l}\text { Ominous/suspicious first stage } \\
\text { cardiotocograph }\end{array}$ & $5 / 5(100)$ & $11 / 19(58)$ & - & $4 / 5(80)$ & $5 / 19(26)$ & $11 \cdot 2(1.0$ to $125 \cdot 6)$ \\
\hline $\begin{array}{l}\text { Ominous/suspicious second } \\
\text { stage cardiotocograph }\end{array}$ & $3 / 3(100)$ & $8 / 13(62)$ & - & $2 / 3(67)$ & $4 / 14(29)$ & $5 \cdot 0(0.4$ to $71 \cdot 9)$ \\
\hline fluid & $3 / 12(25)$ & $4 / 71(6)$ & $5 \cdot 6(1 \cdot 1$ to $29 \cdot 1)$ & $4 / 12(33)$ & $3 / 51(6)$ & $8.0(1.5$ to 42.7$)$ \\
\hline Apgar score $\leqslant 2$ at $5 \mathrm{~min}$ & $4 / 9(44)$ & $25 / 61(41)$ & $1 \cdot 2(0.3$ to $4 \cdot 7)$ & $8 / 11(73)$ & $10 / 48(21)$ & $10 \cdot 1(2 \cdot 3$ to $45 \cdot 4)$ \\
\hline Birth weight $\leqslant 10$ th centile & $16(47)$ & $41(27)$ & $2 \cdot 4(1 \cdot 1$ to $5 \cdot 1)$ & $8(36)$ & $19(28)$ & $1.4(0.5$ to 4.0$)$ \\
\hline
\end{tabular}

FURTHER ANALYSIS BY PRESENCE OF CONGENITAL ANOMALY

No major congenital anomaly

One hundred and eighty five (68\%) of the 274 subjects had no major congenital anomaly; 34 $(18 \%)$ of these non-malformed infants had a white matter lesion and $151(82 \%)$ did not. There was an increased incidence of an antenatal diagnosis of IUGR (OR 3.0; $95 \% \mathrm{CI}$ $1 \cdot 2$ to $7 \cdot 6$ ), oligohydramnios (OR $3 \cdot 0 ; 95 \% \mathrm{CI}$ $1 \cdot 0$ to $9 \cdot 0$ ), meconium stained liquor (OR $5 \cdot 6$; $95 \%$ CI $1 \cdot 1$ to $29 \cdot 1$ ), and birth weight less than the 10 th centile (OR $2 \cdot 4 ; 95 \%$ CI $1 \cdot 1$ to $5 \cdot 1$ ) among non-malformed infants with white matter lesions than those who did not have white matter lesions (table 5 ). Five $(42 \%)$ of 12 of those with lesions and $19(27 \%)$ of 71 of those without lesions were monitored continuously during labour. Of those in whom the cardiotocographs were available for analysis, an ominous or suspicious cardiotocograph was found in all five $(100 \%)$ of those with lesions and $11(58 \%)$ of 19 of those without.

\section{Major congenital anomaly}

Eighty nine $(32 \%)$ of the 274 subjects had a major congenital anomaly; $22(25 \%)$ of these had white matter lesions and $67(75 \%)$ did not. A diverse range of congenital anomalies was found in this group. Most were lethal anomalies such as Potter's syndrome, holoprosencephaly, and trisomy 13, 18, and 21 . Some anomalies such as trisomy 21 were not lethal and the cause of death was either unrelated or death occurred as a consequence of prematurity. When antecedent factors were compared for those with and without lesions in the group with major congenital anomalies (table 5), the association of single maternal marital status and lesions remained at the 5\% level among those with lesions (OR 10.3; 95\% CI 3.0 to $35 \cdot 7$ ). Oligohydramnios (OR $2 \cdot 8 ; 95 \%$ CI 0.7 to 11.4 ) and an antenatal diagnosis of IUGR (OR $2.1 ; 95 \%$ CI 0.7 to 6.8 ) were also more common in those with lesions but the difference was not significant at the $5 \%$ level.

For those who survived until the intrapartum period the presence of meconium stained liquor was increased at the $5 \%$ level (OR $8.0 ; 95 \%$ CI 1.5 to $42 \cdot 7$ ), as was an ominous cardiotocograph in the first stage of labour (OR $11 \cdot 2 ; 95 \%$ CI 1.0 to $125 \cdot 6$ ). An ominous or suspicious cardiotocograph in the second stage of labour was not more frequent. For those who survived delivery there was an increased incidence of an Apgar score of 2 or less at five minutes (OR $10 \cdot 1 ; 95 \%$ CI $2 \cdot 3$ to 45.3).

\section{Discussion}

The main finding in this study was the increased frequency of IUGR and oligohydramnios among infants in whom there was pathological evidence of prenatal white matter damage. These observations are similar to those of Gilles et $a l^{1}$ and Sims. ${ }^{3}$ We did not, however, show associations between prenatal white matter lesions and maternal infection, particularly urinary tract infection, antepartum haemorrhage, and polyhydramnios, which were found in these previous studies. ${ }^{13}$ Increased maternal serum $\alpha$ fetoprotein is known to be associated with pre-eclampsia and IUGR $^{27}$ as well as an increased risk of congenital anomalies. The association of increased maternal serum $\alpha$ fetoprotein and white matter lesions in our study was stronger among non-malformed infants and we presume that this is largely due to the increased frequency of IUGR in the group with lesions. We are unable to explain the association of white matter lesions and unmarried status (particularly in the group with congenital anomalies), and the association of lesions and non-white mothers (particularly in the group without a congenital anomaly). In view of the large number of associations sought it is possible that these are chance findings.

It is possible that chronic hypoxia in the fetus which results in growth retardation and oligohydramnios may also be associated with cerebral ischaemia leading to white matter lesions which can be seen pathologically. In general, both under experimental conditions of intrauterine hypoxia and IUGR ${ }^{28}$ and in the human growth retarded fetus, ${ }^{29-32}$ cerebral perfusion increases without alteration in the regional distribution of blood flow within the brain. ${ }^{33}$ When hypoxia is severe, however, cerebral blood flow may decrease and areas of the brain with a high metabolic rate such as developing white matter may be compromised. This eventual decrease in cerebral blood flow has been shown using Doppler ultrasound 
techniques in severely growth retarded fetuses with oligohydramnios. ${ }^{34} 35$

The relation of prenatal white matter lesions and later cerebral palsy in infants who survive is not clear. In life, the natural history of such brain lesions can be studied by repeated scanning using neuroimaging techniques. This type of longitudinal study can follow the evolution and later clinical manifestations of severe extensive white matter damage which is visible on cranial ultrasound of the fetus or newborn infant. $^{2021}$ Less severe white matter lesions, however, may not be visible on current neuroimaging techniques. It then becomes impossible to study the relation of these lesions and cerebral palsy. Indeed it may be that these mild lesions pose no threat to the neurological integrity of the child.

There is, however, some other evidence which suggests that chronic intrauterine hypoxia, prenatal white matter lesions and cerebral palsy could be causally linked. Firstly, fetal growth retardation and oligohydramnios have previously been found to be associated with cerebral palsy ${ }^{121415}$ and our own work supports this finding (G Gaffney et al, unpublished data). Secondly, a proportion of children with neurological impairment show delayed or abnormal myelination on magnetic resonance imaging. ${ }^{36} 37$ Thirdly, in vitro studies have shown that hypoxia has adverse effects on immature glial cell proliferation and leads to a proportional decrease in oligodendrocyte numbers (S Marret et al, presented at the International Symposium on Fetal and Neonatal Neurology, Tours, October 1991). These cells are responsible for myelination and if this effect also occurred in vivo there may be a reduced capacity for myelin synthesis, resulting in permanent neurological damage and signs of cerebral palsy.

Of considerable clinical interest were the observations that the intrapartum passage of meconium, abnormal cardiotocographs, and low five minute Apgar scores occurred more often in infants with prenatal white matter lesions than in those without. Indeed, nine of the 10 infants with prenatal lesions who were continuously monitored had ominous or suspicious changes on the cardiotocograph in the first stage of labour. It is often assumed that such signs reflect an acute hypoxic intrapartum episode; in this study, however, it is likely that signs of fetal distress also reflected existing prenatal lesions.

Major congenital anomalies were common in this case series and the presence of a congenital anomaly is potentially confounding. Antenatal characteristics, such as growth retardation, which occur with increasing frequency in fetuses and infants with white matter lesions are also more frequent in infants with a congenital anomaly. It is also likely that some congenital anomalies may increase the risk of white matter lesions; for example, an infant with a cardiac malformation may have cerebral hypoperfusion. The association of prenatal white matter lesions and IUGR persisted, however, after adjusting for the presence of congenital anomaly in the analysis. This supports the hypothesis that in non-malformed infants chronic hypoxia is an important contributory factor to white matter damage.

Furthermore, the presence of a congenital anomaly may confound the association of prenatal white matter lesions and fetal distress. Not only may major brain anomaly be associated with an abnormal cardiotocograph, ${ }^{26}$ but signs of fetal distress may be prolonged if it has been decided that no resuscitation will be offered to an infant with a severe anomaly. The association of white matter lesions and fetal distress persisted after adjusting for the presence of congenital anomaly.

Prenatal lesions were remarkably common in this series of brains studied neuropathologically. The series was highly selected but the frequency was consistent with other reported studies. ${ }^{1-3}$ The frequency and distribution of lesions suggests that from 23 to 24 weeks' gestation onwards the white matter of the fetal brain is particularly susceptible to hypoxia or ischaemia. It remains to be determined whether or not the fetus who survives with lesions will have identifiable changes using newer techniques of neuroimaging and the clinical signs of cerebral palsy.

This study was funded by the Department of Health and Action Research.

1 Gilles FH, Leviton A, Dooling EC. The developing human brain: growth and epidemiologic neuropathology. Boston: Wright, 1983

2 Paneth N, Rudelli R, Monte W, et al. White matter necrosis in very low birth weight infants: neuropathologic and ultrasonographic findings surviving six days or longer. $\mathfrak{f}$ Pediatr 1990; 116: 975-84.

3 Sims ME. Brain injury and intrauterine death. Am 7 Obstet Gynecol 1985; 151: 721-3.

4 Ellis WG, Goetzman BW, Lindenberg JA. Neuropathologic documentation of prenatal brain damage. Am $\mathcal{f}$ Dis Child 1988; 142: 858-66.

5 Volpe JJ. Current concepts of brain injury in the premature infant. Am f Radiol 1989; 153: 243-51.

6 Bejar P, Wozniak P, Allard M, et al. Antenatal origin of neurologic damage in newborn infants. $A m \mathcal{F}$ Obstet Gynecol 1988; 159: 357-63.

7 Nelson KB, Ellenberg JH. Antecedents of cerebral palsy. $N$ Engl f Med 1986; 8: 81-6.

8 Blair E, Stanley FJ. Intrapartum asphyxia: a rare cause of cerebral palsy. $\mathcal{F}$ Pediatr 1988; 112: 515-9.

9 Nelson KB. What proportion of cerebral palsy is related to birth asphyxia? f Pediatr 1988; 2: 572-4.

10 Nelson KB. Prenatal origin of hemiparetic cerebral palsy: how often and why? Pediatrics 1991; 88: 1059-62.

11 Nelson KB, Ellenberg JH. Antecedents of cerebral palsy I. Univariate analysis of risk. Am $\mathcal{F}$ Dis Child 1985; 139: 1031-8.

12 Nelson KB, Ellenberg JH. Antecedents of cerebral palsy. Multivariate analysis of risk. N Engl f Med 1986; 315: 81-6.

13 Torfs CP, van den Berg BJ, Oechsli FW, Cummins S. Prenatal and perinatal factors in the aetiology of cerebral palsy. $\mathcal{F}$ Pediatr 1990; 116: 615-9.

14 Uvebrant $P$, Hagberg G. Intrauterine growth in children with cerebral palsy. Acta Pediatr 1992;81: 407-12.

15 Blair E, Stanley FJ. Intrauterine growth and spastic cerebral palsy. Association with birth weight for gestational age. Am $\mathcal{F}$ Obstet Gynecol 1990; 162: 229-37.

16 Banker BQ, Larroche JC. Periventricular leukomalacia of infancy. A form of neonatal anoxic encephalopathy. Arch Neurol 1962; 7: 386-410.

17 De Reuck J, Chatta AS, Richardson EP. Pathogenesis and evolution of periventricular leukomalacia in infancy. Arch Neurol 1972; 27: 229-36.

18 Cooke RWI. Early and late cranial ultrasonographic appearances and outcome in very low birthweight infants. Arch Dis Child 1987; 62: 931-7.

19 Graham M, Levene MI, Trounce JQ. Prediction of cerebral palsy in VLBW infants: prospective ultrasound study. Lancet 1987; ii: $593-5$.

20 Weindling AM, Rochefort MJ, Calvert SA, Fok TF, Wilkinson A. Development of cerebral palsy after detection of periventricular cysts in the newborn. Dev Med tion of periventricular cysts

21 Fawer CL, Calame A, Perentes E, Andregg A. Periventricular leukomalacia and neurodevelopmental outcome in preterm infants. Arch Dis Child 1987; 62: 30-6. 
22 De Vries LS, Dubowitz LMS, Dubowitz V, et al. Predictive value of cranial ultrasound; a reappraisal. Lancet 1985; ii: 137-40.

23 Hope PL, Gould SJ, Howard S, et al. Precision of ultrasound diagnosis of pathologically verified lesions in the brains of very preterm infants. Dev Med Child Neurol 1988; 30: 457-71.

24 Squier MV, Keeling JW. The incidence of prenatal brain injury. Neuropathol Appl Neurobiol 1991; 17: 29-38.

25 Yudkin PL Aboualfa M, Eyre JA, Redman CWG Yudkin PL, Aboualfa M, Eyre JA, Redman CWG,
Wilkinson AR. New birthweight and head circumference centiles for gestational ages 24 to 42 weeks. Early Hum centiles for gestation

26 Boylan P. Intrapartum fetal monitoring. Ballieres Clin Obstet Gynaecol 1987; 11: 73-95.

27 Boyd PA. Why might maternal serum AFP be high in pregnancies in which the fetus is normally formed? $\mathrm{Br} f$ Obstet Gynaecol 1992; 99: 93-5.

28 Ashwal S, Majcher JS, Vain N, Longo LD. Patterns of fetal lamb regional cerebral blood flow during and after prolonged hypoxia. Pediatr Res 1980; 14: 1104-10.

29 Wladimiroff JW. Fetal cerebral blood flow. Clin Obste Gynecol 1989; 32: 710-8.

30 Kirkinen P, Muller R, Huch R, Huch A. Blood flow velocity waveforms in human fetal intracranial arteries. Obstet Gynecol 1987; 70: 617-21.
31 Wladimiroff JW, Noordam MJ, van den Wijngaard JAGW, Hop WCJ. Fetal internal carotid and umbilical artery blood flow velocity waveforms as a measure of fetal wellbeing in intrauterine growth retardation. Pediatr Res 1988; 24: 609-12.

32 van den Wijngaard JAGW, Groenenberg IAL, Wladirmiroff JW, Hop WCJ. Cerebral Doppler ultrasound of the human fetus. Br 7 Obstet Gynecol 1989; 96: 845-9.

33 Clapp JF III, McLaughlin MK, Gellis J, Hemphill C, Catalano PM. Regional distribution of cerebral blood flow in experimental intrauterine growth retardation. $A m f$ Obstet Gynecol 1984; 150: 843-6.

34 van den Wijngaard JAGW, Wladirmiroff JW, Reuss A, Stewart PA. Oligohydramnios and fetal cerebral blood Stewart PA. Oligohydramnios and fetal cer
flow. Br f Obstet Gynecol 1988; 95: 1309-11.

35 Vyas S, Nicolaides KH, Bower S, Campbell S. Middle cerebral artery flow velocity waveforms in fetal hypoxaemia. Br $\mathcal{F}$ Obstet Gynaecol 1990; 97: 797803

36 Harbord MG, Finn JP, Hall-Craggs MA, Robb SA, Kendall BE, Boyd SG. Myelination patterns on MR of children with developmental delay. Dev Med Child Neurol 1990; 32: 295-303.

37 Johnson MA, Pennock JM, Bydder GM, Dubowitz LMS Thomas DJ, Young IR. Serial MR imaging in neonatal cerebral injury. Am $\mathcal{F}$ Radiol 1987; 8: 83-92. 